somewhat patchy and needs to be read with the five chapter appendicies to be coherent. The appendices describe Gaussian springs, Brownian motion, hydrodynamic interaction, stress tensor construction, and finally full solution of the eigenvalue problem. (It is unfortunate, however, that the relaxation time $\tau_{\mathrm{p}}$ is implied on p155 to represent the response of the pth sub-molecule rather than the pth normal mode.) Chapter 11 generalises this material in various ways, including a description of the Oldroyd approach and the use of non-linear time derivatives in modelling. Commentary on many of the models is so brief that a trek to the cited literature is really required.

Chapter 12 on applications comes close to several engineering problems. Again, the treatment is a survey, but this reader found it quite successful: boundary layer theory, converging flow, falling sphere, extensional motion, flow in packed beds, transients, secondary motion, stability theory, extruder analysis, orthogonal rheometer and inclined open channel. Chapter 13 concludes the book with another excursion into the microscopic, 'Suspension Rheology'. Both rigid and deforming particles are considered, with most detail given to dilute emulsions.

Arising from notes used by Professor Schowalter in over ten years of teaching, the book contains homework problems appended to 11 of the 13 chapters and ample references. Few data are given-only three figures show data points, although there are many schematic drawings-and notation is cumbersome in places. However, the writing style is clear and contains a fine flavour of good humour, and relatively few misprints have crept in. One is advised to ignore the purple and lavender cover and use this text as a guide to the wide variety of rheological activity during the modern transition of 1950-75.

Michael C. Williams

Michael C. Williams is Professor in the Department of Chemical Engineering at the University of California, Berkeley.

\section{Atomic absorption spectroscopy}

Atomic Absorption, Fluorescence and Flame Emission Spectroscopy: A Practical Approach. By K. C. Thompson and R. J. Reynolds. Pp. 319. (Charles Griffin: London and High Wycombe, UK, 1978.) $£ 15$.

THE second edition of this book, first published in 1970, includes coverage, in varying detail, of the very extensive advances which have been made in atomic spectroscopy in the intervening years. In some areas, however, the extent of the coverage leaves something to be desired. There is commendable emphasis on safety, of which the reader should take careful note: unfortunately, burner explosions are not unknown.

The book can be considered in two main sections, one being principally chemical and the other instrumental. The chemical section covers very thoroughly the areas of applications, chemical techniques and interferences in atomic absorption spectroscopy (AAS), although some of the instrumental procedures described tend to be somewhat dated. For instance, the inexperienced reader would be forgiven for thinking that digital readout is a rare feature, whereas, in fact, it is incorporated in nearly all present-day instruments. It is also noticeable that strong emphasis is given to the relatively little used hydride technique, whereas the very important area of flameless electrothermal AAS is relegated to the chapter on "Some further techniques"; and it should be mentioned that some authorities claim considerably lower detection limits for

\section{Molecular models}

Molecular and Crystal Structure Models. By A. Walton. Pp. 201. (Ellis Horwood: Chichester, UK, 1978.) £9.

MAKING models of the physical world is the stuff of science. Extending and refining these models is what we are doing when we do research. Nowhere is the concept of models more evident than in chemistry. Both at the detailed level of molecular orbitals and, more commonly, in the consideration of three dimensional structure we consider molecules to be representable by models which we can imagine actually constructing as tangible objects.

Dr Walton's book surveys most of the commercially available molecular models and contains advice on do-ityourself versions. The survey is not exhaustive (an exhaustive survey would soon date), but it is sufficiently wide to be a useful first step for anyone looking for a particular feature.

Models showing special features or behaving in special ways are commonly constructed in research and this book will provide useful tips for that would-be modeller. It is, however, to some elements than those given in the table on pages 33 and 34 .

On the instrumental side, it seems that the authors have a bias against double-beam instruments and the reader is advised to be cautious in accepting the advice given. It is also felt that the guidance on performance parameters could be clearer for the inexperienced user. Again, it is noticeable that only brief mention is made of microprocessor-based instruments, although these now represent a high proportion of those available.

Flame emission and atomic fluorescence spectroscopy are covered in a separate chapter, primarily from the the point of view of comparison with AAS. In this respect, an unfortunate weakness is the fact that the very important and competitive (with AAS) technique of plasma emission is dismissed in five lines.

A very extensive bibliography is given at the end of each chapter, but it might have been appropriate to mention that a complete atomic absorption bibliography is available. Overall, the book can be recommended to both new and more experienced users of AAS from the chemical standpoint but with reservations on the instrumental side.

M. A. Ford

M. A. Ford is Technical Director of Perkin-Elmer Limited, Beaconsfield, UK.

the teacher that it will most appeal, providing as it does descriptions of most of the off-the-shelf models, and photographs of many. In it one should be able to find the (non-ideal) model which is a good compromise and which can be provided within the departmental budget for a class of students.

Apart from being inexhaustive, the book suffers from, inevitably, describing each model in a different way. It is particularly unfortunate that it was not possible to have photographs of every model type. This makes it difficult to use for searching out models of a particular type, but it does make it readable. The principal deficiency is, however, the lack of information on consumer-response-is it easy for students to see the point the lecturer is making? Do the students like building these models and do they understand the principles that they are supposed to demonstrate? What are their deficiencies? Perhaps the only answer, as every teacher wishes to emphasise different aspects, is to use this book (with its extensive crossreferencing) to narrow down the choice and then try the models oneself.

S. D. Dover

S. D. Dover is Lecturer in Biophysics at King's College, University of London, $U K$. 